\title{
A Synoptic and Theoretical Account of Character (Digits and Capital Letters) Reversal in Writings by Typically Developing Children
}

\author{
Jean-Paul Fischer $*$ (D) and Christophe Luxembourger \\ Department of Psychology, Laboratory 2LPN, University of Lorraine, 54021 Nancy, France; \\ christophe.luxembourger@univ-lorraine.fr \\ * Correspondence: jean-paul.fischer@univ-lorraine.fr
}

Received: 15 June 2018; Accepted: 30 August 2018; Published: 2 September 2018

\begin{abstract}
Reversing characters (digits and letters) when writing, and complete mirror writing, raise one of the oldest and most mysterious questions in developmental and educational psychology: Why do five-year-old children write symbols (e.g., $\exists$ for E) they have neither learnt nor seen? Attempts to draw up a complete explanatory theory of character reversal in writings by typically developing children were long hindered by the existence of a seemingly satisfactory explanation (left-hand writing), the failure to bring together research in neuropsychology and educational psychology, and the failure to consider the shape and structure of the characters. The present paper remedies this situation by describing a new, comprehensive theory based on recent neuropsychological findings and extensive empirical observations. The theory assumes that a character's orientation, detected in the early visual processing area, is deleted (or made inaccessible) by the mirror generalization process during transfer to memory. Consequently, there is a period, usually around age five, during which children have representations of the characters' shapes but not their orientations. Hence, when asked to write a character, children have to improvise its orientation, and the orientation they choose (implicitly, non-consciously) is often derived from the writing direction in their culture.
\end{abstract}

Keywords: mirror writing; mirror copying; mirror generalization; digit reversal; capital letter reversal

\section{Introduction: Historical Background}

Character reversal, which results in left-right reversed characters (letters and digits) that appear normal when read in a mirror, is a major component of mirror writing. In the scientific literature, it was first described in 1878 by Buchwald, who reported several cases of character reversal in writing by patients with brain lesions and by healthy individuals, most notably children, nearly all of whom wrote with their left hand [1]. This pioneering study launched a new field of research and triggered numerous reports of mirror writing by both pathological and non-pathological individuals. Less felicitously, Buchwald's implicit suggestion that mirror writing was restricted to people who wrote with their left hand, whether naturally or deliberately, would cloud research for over a century.

Erlenmeyer immediately included Buchwald's paper in his book on "Writing", quoting at length the paragraph describing children who mirror wrote with their left hand, but, when alerted to the incorrectness of their writing, wrote correctly with their right hand [2]. Furthermore, by suggesting "abductive left-hand writing" (linkshändige Abductionsschrift in German) as a more appropriate name for "mirror writing", Erlenmeyer reduced mirror writing to a mechanistic result of writing with the left hand: Characters and words are reversed when an individual writes abductively (outwards from the body midline) with the left hand. 
Nevertheless, some early authors rejected the inference-that mirror reversal is closely linked to writing with the left hand-induced from Buchwald's seminal paper. For example, Hale and Kuh, in 1901, wrote unequivocally: "Almost every child at a certain period of its development will be found to produce spontaneous mirror-writing, and that, too, with its right hand" [3] (p. 1382). However, Buchwald's influence, supported by Erlenmeyer's abductive left-hand writing explanation, was so strong that, in 1936, an author claimed, with a certain amount of pride, to be the first author to publish a case of mirror writing by a "right-eyed child" who showed no left-handed tendencies [4].

Hildreth's discussion of character reversal and mirror writing in her fourth seminal paper on "The development and training of hand dominance", which she subtitled "Developmental problems associated with handedness", further reinforced the association between mirror reversal and writing with the left hand [5]. This idea was tested in a group of 72 children with a mean age of 5.5 years, 36 of whom wrote with their left-hand and 36 of whom wrote with their right-hand [6]. Although the resulting data indicated a possible link between a character's shape and the frequency with which it was reversed, neither the author nor others followed up on this finding. These results may have had little impact, because they did not support predictions relating character reversal to handedness [7].

Consequently, claims such as "In countries where script normally runs from left to right, young children who spontaneously produce mirror-writing are generally left-handers" [8] (p. 356) were still widely accepted at the end of the 20th century, and paediatricians were still taught that "one unifying feature of mirror writing is the fact that it is almost always executed with the left hand" [9] (p. 16). In fact, this misconception was not successfully challenged until the publication of an important paper in which the authors emphasized that "left-handed children had no more probability than right-handers of developing mirror writing" [10] (p. 16). This review of research led the authors of the paper to propose a possible unified explanation for mirror writing in both pathological adults and typically developing young children, which they labelled the "directional apraxia theory". However, finding that children do not display adult-like mirror discrimination of letters indirectly weakens the idea that a single theory can explain character reversal in both adults and children [11], and the results of neurological studies [12,13] directly challenge the validity of the theory.

If, as seems to be the case, different explanations are needed to account for mirror writing by adults and mirror writing by children, then data on mirror writing by adults, whether deliberate [14] or not [15], are unlikely to throw light onto mirror reversals by 5 -year-old children. What is more, data for adults do not suggest a possible role of character shape as a factor in explaining why children mirror write the characters. In contrast, recent neuropsychological findings and large-scale empirical studies of children suggest that this parameter may be the key to understanding why typically developing children reverse characters when they write.

\section{Recent Neuropsychological Findings}

"Animals may appear in mirror-opposite profiles, danger may lurk on either side" [16] (p. 25). This suggests that evolution has forged the process of mirror generalization, which is at work in very young children, even babies [17]. Moreover, traces of this mirror generalization of characters can still be found in adults [18], at least in the case of non-reversible letters [19]. Not surprisingly, learning to read and handwrite the Latin alphabet increases the ability to discriminate mirror images [20,21], breaks mirror-invariance [22], and transforms the brain more generally [23,24]. According to a prominent theory, this mirror generalization for letters and words is due to the recycling of neurons in an area called the Visual Word Form Area (VWFA), which originally developed to recognize objects [25-27]. Because mirror generalization for objects and animals is often advantageous (as in the example of being able to memorize, and therefore recognize, dangerous animals), neurons in the VWFA have been dedicated to it. The recycled neurons may have inherited the mirror generalization process for characters from the object recognizing neurons in the VWFA. Insights into the neurobiological basis of this mirror generalization process are being provided by three lines of recent research. 
Research on macaque monkeys has shed light on the hierarchical processing that occurs in the ventral visual pathway (see [28], for humans), but the question remains: How many stages are there, and how do they function together? Inferotemporal cells with mirror-symmetric tuning were already reported in [29], but a new study showed that such cells are agglomerated within an intermediate patch [30]. Precisely, the macaque's face-processing network was studied by recording neurons from two middle face patches (ML, middle lateral, and MF, middle fundus) and two anterior face patches ( $\mathrm{AL}$, anterior lateral, and $\mathrm{AM}$, anterior medial). Neurons in the ML and MF were view specific; neurons in the AL were tuned to identify mirror-symmetric views, and neurons in the AM, the most anterior face patch, achieved almost full view invariance. The finding that one region (AL) contains neurons with mirror-symmetric tuning is particularly important, because it suggests that a representation confounding two symmetrical faces is a single intermediate node within a shape-processing network.

In contrast with studies demonstrating mirror-image confusion for objects, searchers observed that the navigability of a scene changes when it is mirror reversed [31]. This observation led them to conduct an experiment in which they used event-related functional Magnetic Resonance Imaging to determine which representations are unaffected by mirror reversal in humans. Their results showed tolerance to mirror reversals in one object-selective region and the posterior fusiform sulcus, and great sensitivity to these reversals in two scene-selective regions. However, a more posterior (in the brain) object-selective region, the lateral occipital sulcus, also showed sensitivity to mirror reversals, suggesting that orientation information is represented at earlier stages in the object-processing hierarchy.

Even Related Potential was used to investigate how the brain encodes the geometric information underlying object shape and orientation [32]. Adult participants were shown between three and five context images and then presented with a test-image in which either the shape or the left-right orientation was changed or not changed. Results showed that (1) the early posterior P1 ( 100 ms) orientation response was more positive than the shape response; (2) the mid-latency central P2 ( $\sim 175 \mathrm{~ms}$ ) shape response was more positive than the orientation response; and (3) the mid-latency central N4 ( $400 \mathrm{~ms}$ ) orientation response was more positive than the shape response. According to the authors, these differences may reflect the detection of low-level orientation information in early visual areas, the reliance on mirror-invariant shape in later visual areas, and the effortful detection of orientation information even later in visual processing.

Taken together, these neuropsychological findings suggest that the visual image of an object (e.g., a digit or letter) is distinguished from its mirror image at an early stage of processing. Then, a process called mirror generalization $[16,25]$ leads to these two images becoming undistinguishable at an intermediate stage. The distinction is restored at a later stage, when an individual is required to make the distinction. The two first stages of this process of mirror generalization seem particularly important for understanding character reversal in children.

Initially, children mostly learn to recognize characters by seeing them in their surroundings, and they often learn to write characters and their name by copying them from models provided by parents, teachers, or exercise books. French preschool and first grade classrooms generally facilitate this learning by displaying the letters of the alphabet and the 10 Arabic numerals on the walls. Furthermore, nearly all teachers at France's preschools provide children in their upper section classes (5- to 6-year-old) with a number line to encourage them to write the digits by themselves.

Consequently, determining how the visual system initially processes characters when they are seen seems fundamental. Because of the initial distinction between an image and its mirror, evidenced by these neuropsychological findings, we can predict that children should have few difficulties in copying the characters orientation correctly; this was verified in the following Section 3.3. However, when the mirror generalization process is at work, children will probably find it difficult to orient characters when writing them from memory. This will likely lead to frequent reversals, regardless of whether the child writes with their usual right- or left-hand. This was verified in Sections 3.1 and 3.2. Furthermore, when children do not know the characters orientation, one can hypothesize that they will adopt, at least implicitly, a general strategy. This strategy was evidenced in the empirical work reported in Sections 3.1 and 3.4. 


\section{Recent Empirical Findings}

Previous theories have attributed character reversal and mirror writing to left-hand writing. Although these theories have been long accepted, they are not consistent with recent neuropsychological findings. The following paragraphs focus on four main recent empirical findings that are consistent with these neuropsychological findings and comprehensively disprove the old theories.

\subsection{Children Reverse the Different Characters Frequently but Unequally}

Tables 1 and 2 show reversal percentages-calculated with respect to the total number of correct and reversed productions-for writings of digits and capital letters, as recorded during a series of studies in the same laboratory [33-39]. In the case of the digits, these studies involved a total of 1563 children. As the means show, the characters that appear left-oriented (1, 2, 3, 7, 9, J, and Z) were reversed more frequently, sometimes considerably more frequently, than the characters that appear right-oriented (we will closely go into the notion of left- and right-orientation in Section 4). For example, reversal percentages for 3, J, and $\mathrm{Z}$ were around $50 \%$, whereas reversal percentages for $\mathrm{K}$ and $\mathrm{N}$ were less than $5 \%$.

Table 1. Percentage reversals of the eight asymmetrical digits as a function of the digit in different studies.

\begin{tabular}{ccccccccccccc}
\hline Ref. Study & $\mathbf{N}^{\mathbf{a}}$ & $\mathbf{M}_{\text {age }}$ & $\mathbf{1}$ & $\mathbf{2}$ & $\mathbf{3}$ & $\mathbf{4}$ & $\mathbf{5}$ & $\mathbf{6}$ & $\mathbf{7}$ & $\mathbf{9}$ & $\boldsymbol{n}^{\mathbf{b}}$ & $\mathbf{M i x e d ~}^{\mathbf{c}}$ \\
\hline [33] $^{\mathrm{d}}$ & 256 & 5.58 & 31 & 26 & 46 & 16 & $32 \mathrm{e}$ & 18 & 32 & 44 & 2 & no \\
{$[34]$} & 300 & 5.72 & 42 & 46 & 66 & 12 & 15 & 16 & 45 & 44 & 1 & yes \\
{$[35]$} & 153 & 5.75 & 22 & 28 & 45 & 9 & 11 & 18 & 22 & 19 & $1^{\mathrm{f}}$ & no \\
{$[36]$} & 367 & 5.64 & 32 & 32 & 45 & 11 & 23 & 26 & 39 & 40 & 4 & no \\
{$[37]$} & 189 & 5.65 & 39 & 33 & 60 & 8 & 8 & 13 & 40 & 27 & $1 \mathrm{~g}$ & yes \\
{$[38]$} & 298 & 5.74 & 25 & 30 & 39 & 12 & 21 & 22 & 31 & 35 & 4 & no \\
\hline \multicolumn{2}{l}{ Simple mean } & 5.68 & 31.8 & 32.5 & 50.2 & 11.3 & 15.6 & 18.8 & 34.8 & 34.8 & & \\
Weighted mean & 5.68 & 30.4 & 31.6 & 49.3 & 11.8 & 20.1 & 21.9 & 35.4 & 38.6 & & \\
\hline
\end{tabular}

\footnotetext{
${ }^{a}$ Number of participants in the referred study; ${ }^{b}$ number of writings solicited per digit and per child; ${ }^{\mathrm{c}}$ writing of the digits was mixed with writing of the capital letters; ${ }^{\mathrm{d}}$ In this study, the children had to write the digit in the cells of a $3 \times 3$ table; in all the other studies, they wrote the digit in a line of adjacent cells $(1 \times 9$ or $1 \times 10$ table $)$; ${ }^{\mathrm{e}}$ This was the only study in which a not completely reversed 5 (i.e., when only the horizontal line was reversed, or when only the curve was reversed) was counted as a reversal. This data (for 5) was not included in the calculation of the means; ${ }^{\text {f }}$ three writings for the digits 3 and 9 ; $g$ three writings for the digit 3.
}

Because these wide-ranging data come from the same laboratory, it is important to mention that many other recent and independent findings are consistent with the relative frequency of the character's reversal suggested by the data. Thus, even if this other research was not aimed at establishing the frequency of reversal of the characters, one can note that (1) a study on 44 Scottish children $\left(M_{\mathrm{age}}=6.82\right.$, from 4.6 to 10.3) who wrote the uppercase letters found that the likelihood of reversal for J and $\mathrm{Z}$ was elevated both in writing with the dominant and non-dominant hands [40]; (2) A training study on 30 French children $\left(\mathrm{M}_{\mathrm{age}}=4.63\right.$, from 4.25 to 5$)$ found more than $50 \%$ reversals for $1,3, \mathrm{~J}$, and $\mathrm{Z}$, and less than $10 \%$ for B, E, N, R and S, which were the only asymmetrical characters studied [41]. 
Table 2. Percentage reversals of the fifteen asymmetrical capital letters as a function of the letter for different studies.

\begin{tabular}{ccccccc}
\hline Ref. Study & [39] & [34] & [35] & [37] & \multicolumn{2}{c}{ Mean } \\
\hline$T^{\mathrm{a}}$ & 47 & 300 & 143 & 189 & Simple & Weighted \\
$\mathrm{M}_{\text {age }}$ & 5.97 & 5.72 & 5.75 & 5.65 & 5.77 & 5.72 \\
$n^{\mathrm{b}}$ & 1 & $1^{\mathrm{c}}$ & 1 & $1^{\mathrm{d}}$ & & \\
mixed $^{\text {e }}$ & no & yes & no & yes & & \\
$\mathrm{B}$ & 2.1 & 4.4 & 11.9 & 6.8 & 6.30 & 6.49 \\
$\mathrm{C}$ & 2.1 & 8.0 & 16.8 & 13.4 & 10.08 & 10.95 \\
$\mathrm{D}$ & 1.1 & 5.8 & $-\mathrm{f}$ & 7.8 & 4.90 & 6.09 \\
$\mathrm{E}$ & 6.4 & 5.1 & 14.0 & 7.9 & 8.35 & 7.84 \\
$\mathrm{~F}$ & 3.2 & 7.9 & $-\mathrm{f}$ & 9.6 & 6.90 & 8.09 \\
$\mathrm{G}$ & 5.3 & 7.7 & $-\mathrm{f}$ & 4.3 & 5.77 & 6.29 \\
$\mathrm{~J}$ & 74.5 & 47.6 & 37.8 & 48.6 & 52.13 & 47.86 \\
$\mathrm{~K}$ & 0.0 & 3.9 & $-\mathrm{f}$ & 6.9 & 3.60 & 4.62 \\
$\mathrm{~L}$ & 1.1 & 12.9 & 11.2 & 10.8 & 9.00 & 11.14 \\
$\mathrm{~N}$ & 1.1 & 2.2 & $-\mathrm{f}$ & 3.2 & 2.17 & 2.46 \\
$\mathrm{P}$ & 0.0 & 8.9 & $-\mathrm{f}$ & 7.7 & 5.53 & 7.70 \\
$\mathrm{Q}$ & 14.9 & 9.7 & $-\mathrm{f}$ & 18.0 & 14.20 & 13.08 \\
$\mathrm{R}$ & 3.2 & 5.9 & 9.8 & 5.5 & 6.10 & 6.42 \\
$\mathrm{~S}$ & 19.1 & 18.4 & 21.0 & 18.5 & 19.25 & 19.02 \\
$\mathrm{Z}$ & 58.5 & 51.4 & 44.8 & 54.1 & 52.20 & 51.32 \\
\hline
\end{tabular}

${ }^{a}$ Number of participants in the referred study; ${ }^{b}$ number of writings solicited per letter and per child; ${ }^{c}$ three writings for the letters $\mathrm{J}$ and $\mathrm{Z} ;{ }^{\mathrm{d}}$ three writings for the letter $\mathrm{J} ;{ }^{\mathrm{e}}$ writing of the capital letters was mixed with writing of the digits; ${ }^{\mathrm{f}}$ not tested.

\subsection{Children Who Write with the Right Hand Reverse the Characters as Well as Those Who Write with the Left Hand}

The data presented in Tables 1 and 2 clearly show mirror reversal of characters can in no way be equated with left-hand writing (see also the children in Figure 1). The approximately $50 \%$ reversal rates for the digit 3 and the letters $J$ and $Z$ could not have been obtained if only left-handed children, even if they made up $15 \%$ of the general population, had reversed these characters, even if they had done so systematically.

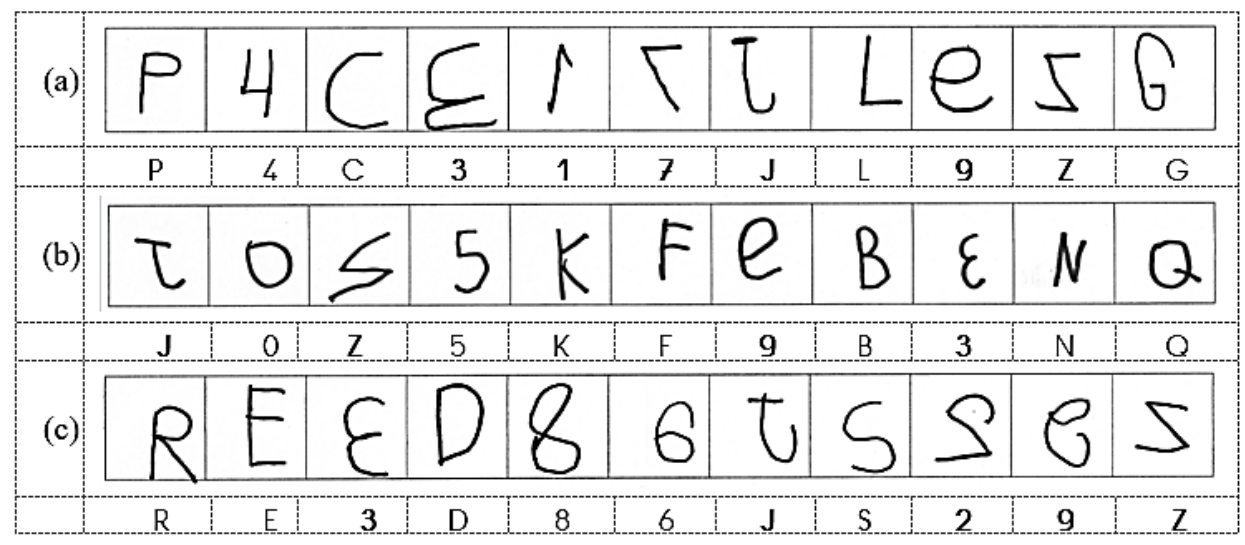

Figure 1. Writings of a series of dictated characters by (a) a boy aged 5 years 3 months, (b) a girl aged 6 years 2 months, and (c) a boy aged 5 years 8 months; all of them spontaneously wrote with their right hand (data from [35], Expt 2). (The mirror-reversed characters are shown in bold below the child's writings).

The claim that right-handed children develop mirror writing as well as left-handed children (see Section 1) was tested in 5-to-6-year-old children who spontaneously wrote either with the right hand or with the left hand. A distinction can be made between quantitative and qualitative comparisons of 
reversal. A quantitative comparison compares the total percentages of character reversals between groups, whereas a qualitative comparison compares groups with respect to the hierarchy of the frequencies of reversals of the different characters (e.g., was 3 the most frequently reversed digit and 4 the least frequently reversed digit in each group?).

The comparison between 59 children who wrote the characters and name with their left hand and 59 children matched for age and school-class who wrote the same material with their right hand showed no quantitative difference in mirror reversal between these two groups of children [42]. Also, given our distinction, the preceding study found no qualitative difference between children who write with their right hand and those who write with their left hand. The left-oriented characters (notably 3, J, and Z) were the most reversed characters in both groups of children. The correlation between the frequencies of reversal of the characters in the two groups was very strong, $r(21)=0.962$. A further study confirmed the lack of a qualitative difference between reversal in the two groups but suggested a slightly greater frequency of reversal in children who wrote with the left hand [38] (see also [35], Expt 1a).

Comparison of Figures 1 and 2 proves the lack of a qualitative difference between children who write with their usual left hand and those who write with their usual right hand. The girl reported in Figure 2, who spontaneously wrote with her left hand, reverses exactly the same (left-oriented) characters as the children reported in Figure 1, all three of whom spontaneously wrote with their right hand.

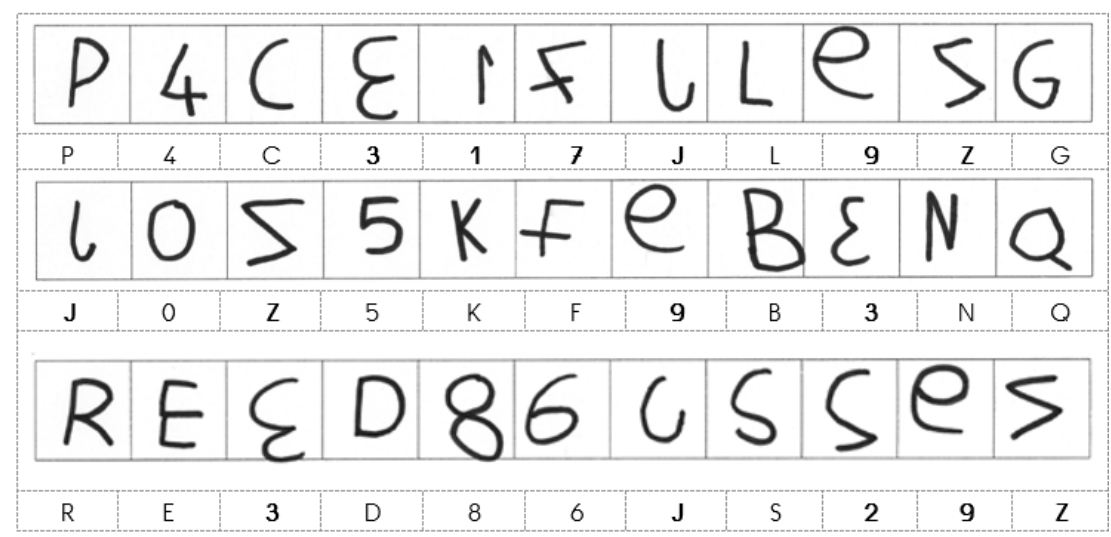

Figure 2. Writings of three series of independently dictated characters by a girl aged 5 years 10 months, who spontaneously wrote with her left hand (data from [35], Expt 2). (The mirror-reversed characters are shown in bold below the child's writings).

\subsection{Children Rarely Reverse the Characters When Copying Them}

An experiment involving children with a mean age of 5.75 years compared reversal percentages obtained for a copying task with those obtained for a writing-from-memory (under dictation) task [35] (Expt 1a). The material consisted of the eight asymmetric digits and eight asymmetric capital letters (see Table 3). In one condition, 143 children copied the digits and wrote the letters from memory; in the second condition, a different group of 156 children copied the letters and wrote the digits from memory. The result was very clear (Table 3 ): The children reversed the characters much less frequently when they copied them than when they wrote them from memory. In fact, they rarely reversed the characters when copying them. 
Table 3. Comparison of reversal frequency for each character in a copying task and in a writing (from memory, under dictation) task (calculated from Table 1 in [35]).

\begin{tabular}{ccccccc}
\hline \multirow{2}{*}{ Digit } & \multicolumn{2}{c}{ Percentage Reversal } & & \multicolumn{2}{c}{ Percentage Reversal } \\
\cline { 2 - 3 } \cline { 6 - 6 } & Copying & Writing & Letters & Copying & Writing \\
\hline 1 & 0.0 & 22.2 & $\mathrm{~B}$ & 0.7 & 11.9 \\
2 & 0.7 & 28.1 & $\mathrm{C}$ & 0.0 & 16.8 \\
3 & 0.7 & 45.1 & $\mathrm{E}$ & 0.0 & 14.0 \\
4 & 0.7 & 9.2 & $\mathrm{~J}$ & 0.0 & 37.8 \\
5 & 0.0 & 11.1 & $\mathrm{~L}$ & 0.0 & 11.2 \\
6 & 0.0 & 17.6 & $\mathrm{R}$ & 0.0 & 9.8 \\
7 & 0.0 & 22.2 & $\mathrm{~S}$ & 0.7 & 21.0 \\
9 & 0.0 & 19.0 & $\mathrm{Z}$ & 2.6 & 44.8 \\
\hline Mean & 0.3 & 21.8 & Mean & 0.5 & 20.9 \\
\hline
\end{tabular}

Indirect confirmation of the easiness of correctly (i.e., without reversing) copying the characters compared to correctly writing them from memory was provided by two studies showing that 4-year-old children make considerably fewer mirror reversals in copying the characters than 5-year-old children in writing the characters from memory (under dictation). First, a cross-sectional study found that 205 children in the middle section of preschool (4- to 5- year-olds) produced only $7.32 \%$ reversals in copying the digits, whereas 153 children in the upper section (5- to-6-year-olds) produced $21.81 \%$ reversals in writing the digits from memory [35] (Expt 1). Second, a longitudinal study found that the 166 children in the middle section produced only $3.62 \%$ reversals in copying the characters, whereas the same children in the upper section produced $25.39 \%$ mirror reversals in writing the characters from memory [43]. If the process of copying did not fundamentally differ from the process of writing from memory-specifically, in being easier-developmental psychology would find it difficult to explain why children in the middle section of preschool produced considerably less reversal errors than the children in the upper section.

\subsection{Children Reverse Right-Oriented Letters When Writing from Right to Left}

The children reported in Table 2, who live in a Western culture with a left-to-right writing direction, reversed the left-oriented letters ( $\mathrm{J}$ and $\mathrm{Z}$ ) far more frequently than the other letters (e.g., $\mathrm{K}, \mathrm{N}$ ). Would these children have reversed the same letters if they wrote from right to left? "Further studies are needed to clarify the role of writing direction in mirror writing and letter inversion phenomena" [44] (p. 82).

One way to do this would be to compare mirror reversals in cultures with different writing directions, but this is not easy to do for a number of reasons (e.g., the characters may be different). Consequently, many researches [35,37,41-43] applied a technique devised in [45] to observe spontaneous mirror writing of their name (or words) by young children. The technique consists of asking children to write their name on sheets of paper bisected by a vertical line, and to start writing at a dot near the bisecting line, sometimes to the left of the line and sometimes to the right. When the dot is to the left of the line, young children typically write from right to left. This technique allows one to analyze character reversals when children spontaneously write from right to left, rather than from left to right (the usual writing direction for these children). Figure 3 provides a few illustrative examples of the resulting observations. Many children reversed the right-oriented letters of their name when they wrote from right to left, even though they wrote these same letters correctly when they wrote from left to right. CYPRIEN, for example, correctly wrote C, P, R, E, and N when he wrote from left to right, but reversed these same letters when he wrote from right to left. Thus, children appear to orient the characters (at least the letters) in the direction of writing [46]. In other words, they tend to reverse the right-oriented letters (B, C, D, E, F, G, K, L N, P, Q, R, and S) when writing from right to left and to reverse the left-oriented letters when writing from left to right ( $\mathrm{J}$ and $\mathrm{Z})$. 


\begin{tabular}{|c|c|c|}
\hline Child & Left-to-right writing & Right-to-left writing \\
\hline $\begin{array}{c}\text { Boy, } 6.11 \text { years, spontaneously } \\
\text { wrote with the right hand }\end{array}$ & & \\
\hline $\begin{array}{c}\text { Girl, } 5.19 \text { years, spontaneously } \\
\text { wrote with the right hand }\end{array}$ & & \\
\hline $\begin{array}{c}\text { Boy, } 5.68 \text { years, spontaneously } \\
\text { wrote with the right hand }\end{array}$ & & \\
\hline $\begin{array}{c}\text { Girl, } 5.26 \text { years, spontaneously } \\
\text { wrote with the left hand }\end{array}$ & & \\
\hline $\begin{array}{l}\text { Boy, } 5.91 \text { years, spontaneously } \\
\text { wrote with the right hand }\end{array}$ & $R O M A \mid N$ & \\
\hline $\begin{array}{l}\text { Girl, } 5.40 \text { years, spontaneously } \\
\text { wrote with the right hand }\end{array}$ & & \\
\hline
\end{tabular}

Figure 3. Name writings as a function of writing direction by a sample of six children (data from [35,43]). (Written informed consent to publish name writings was obtained from each child's legal guardian).

In the training study [41], there were in fact two conditions designed to compare production of normal versus mirror writing of characters. In the already reported normal condition (see Section 3.1), the trained preliterate children reversed mainly the left-oriented characters. However, when mirror writing was elicited with the previously described technique, they reversed mainly the right-oriented characters. The differences between the two (normal versus mirror writing) conditions were not only significant but also impressive. For example, in the mirror writing condition, 29 (out of 30) children reversed the letter $\mathrm{B}$, but no one child reversed this letter in the normal writing condition. The authors underscore that these results indicate a main contribution of writing directionality to letter and digit reversals. Consequently, they confirm the predominant contribution of writing directionality to mirror writing in typically developing children [46].

\section{A Theory of Character Reversal in Writing from Memory}

Our theory, outlined in the following paragraphs, builds on the recent neuropsychological findings described in Section 2, which explain why children reverse characters but not why they reverse some characters $(3, \mathrm{~J}$, and $\mathrm{Z})$ about 10 times more frequently than others $(\mathrm{K}, \mathrm{N})$. The theory's first tenet is that 5 -year-old children have no difficulty visually discriminating a character from its mirror (i.e., they see that the two differ). Two main observations support this claim. First, when asked to copy characters, 5to 6-year-old children generally write them correctly. Second, neurophysiological studies have shown that information about orientation is encoded in early visual areas.

However, the neurophysiological mirror-generalization process may lead this initial information on orientation being lost during memory transfer along the visual ventral occipito-temporal pathway (see [47] for more information about this pathway). As a result, there is a short period of time during which children master the shape of the characters but not their left-right orientation. During this period, if children are asked to write a character under dictation (i.e., from memory), they often solve the dilemma of which way to orient the character by implicitly and non-consciously orienting it in the direction of writing, that is, toward the right in a left-to-right writing culture. Consequently, the characters they reverse most frequently are the left-oriented digits $(1,2,3,7$, and 9$)$ and capital letters ( $\mathrm{J}$ and $\mathrm{Z}$ ).

The notion of "left-oriented" (or "right-oriented") characters is one of the theory's cornerstones. Up to this point, the definition of this notion used in the present paper has been merely intuitive. In an 
attempt to produce a more precise definition, a theoretical analysis of the shapes of the characters was carried out [7]. The results allowed one to highlight a number of similarities in the shapes of Latin letters (see also [48]), many of which (B, D, E, F, K, L, P, and R) consist of a long vertical stroke combined with a distinctive feature to the right of this stroke. When the writing begins with the vertical stroke, the distinctive feature must be added on the right, so the letter appears to be "right-oriented". Similarly, the digits 1 and 7 consist of a long vertical stroke (approximately vertical for 7 ) with a distinctive feature to the left and therefore appear to be "left-oriented". However, this approach cannot be applied to characters without a vertical stroke (e.g., 2, 3, 6, 9, C, and Q), which have to be defined as left- or right-oriented on the basis of other features. In addition, the digit 4 is a case apart: Because children pay particular attention to acute angles [49], and because the acute angle at which the writing of 4 normally starts opens rightwards, the digit 4 can be categorized as "right-oriented".

Given the difficulty of producing a mathematical definition for left- and right-oriented characters, researchers have adopted an empirical approach $[38,50]$. The results of a study in which adult students were asked to rate the orientation of all the asymmetric capital letters and digits support the intuitive definition, as the only digits to be classified as right-oriented were 4,5 , and 6 , and the only letters to be considered left-oriented were J and Z [38]. Furthermore, there was a very strong correlation between the way the capital letters were rated by American students [50] and by French students [38].

A first theorization of orienting the characters towards the right proposed an implicit right-writing or right-orienting rule as underlying the choice of the children [36]. However, given the finding reported in Section 3.4, this rule should better be seen as an instantiation of a more general, possibly universal, rule, which consists of writing or orienting the character in the direction of writing.

A subtle prediction arising from the theory is that children who reverse the left-oriented characters most frequently will reverse the right-oriented characters least frequently, because these children strictly respect the direction of writing. If this is the case, there should be a negative correlation between reversals of the left-oriented characters and reversals of the right-oriented characters. However, such a negative correlation is not easy to establish, because any experiment including whole classrooms is likely to include children who know how to write almost all the characters and who therefore contribute to a positive correlation; the same holds for children who know the shapes of very few characters. Nevertheless, this negative correlation was demonstrated in children of the French preschool upper section, $r=-0.337, p<0.001$ [36], and $r_{\mathrm{S}}=-0.402, p<0.001$ [43]. Likewise, in a training study with letter-like characters in primary schoolchildren (aged 4.8-5.8 years), a negative correlation was found between reversal rates for left- and right-facing characters, $r_{\mathrm{S}}=-0.47, p=0.02$ [51].

\section{Discussion}

\subsection{Are There Some Other Explanatory Factors?}

By emphasizing the importance of the characters' orientations in explaining why they are reversed, the theory indirectly minimizes other potential explanatory factors. Among the latter, the factor "hand of writing" is the most prominent. Our prediction is that these factors play a very minor role in explaining reversal. The direct comparison of children who spontaneously write with their left hand and those who spontaneously write with their right hand clearly shows that the hand of writing does not influence quality of reversal (see Section 3.2). The lack of a qualitative difference between children who write with their left hand and children who write with their right hand is strong evidence against the left-hand abduction explanation of character reversal. There remains the possibility of a very slight quantitative tendency for children who write with their left hand to produce more reversals than children who write with their right hand. Anyway, this explanation of reversal is considerably less relevant than the explanation through the orientation of the characters (see the discussion and demonstration in [38]).

A less prominent potential explanatory factor than "hand of writing" is sex. An old and ambiguous statement, which reported that "most observers find mirror writing more common among boys than 
girls in proportion greater than three to one" [5] (p. 69), and psycho-analytic theory [52], suggests that character reversal concerns mainly boys. Consequently, it is noteworthy to underscore that the massive results obtained in the same researches as that referred in Tables 1 and 2 did not reveal any quantitative or qualitative differences in character reversals between girls and boys.

An educational explanation for some character reversals is that they result from children being taught to draw circles (or segments of circles) counter-clockwise. The reason teachers, parents, and writing books (at least in France) teach children to draw circles counter-clockwise is to help them later when they learn to write cursively from left to right. This explanation for reversals, which holds (and not always) only for the curved characters, can be encompassed by the theory because it may determine a child's implicit choice of orientation. For example, a child who does not know the orientation of the semi-circles composing the digit 3 may simply apply the motor gesture learnt for drawing circles and therefore reverse the 3 .

\subsection{Is There a Role for a Motor-Related Memory?}

By emphasizing the visual component of learning in explaining why characters are reversed, the theory minimizes the possible role of a motor-related memory in the characters orientation. This possibility is connected to the general question of the role of handwriting in the memorization of the writing of the characters. This question is nowadays exacerbated by the use of phones, tablets, and computers, which challenges the utility of learning handwriting. Whereas handwriting is a motor act [53], taught by all teachers in primary school, is it not paradoxical to up hold that motor memory plays only a secondary role in the initial memorization of the characters' orientation? Indeed, some authors suggest that writing movements contribute to memorizing the shape and orientation of characters [54,55]. However, this contribution seems better suited to the learning of the non-oriented shapes than to the learning of their orientation. Moreover, a developmental study of writing suggests that it is certainly not before age 10 that motor automatisms alone can explain writing [53]. Also, by preventing the visual feedback, proprioceptive recognition of letters develops more slowly than visual recognition in 4- to 6-year-old children [56].

A partial answer to our question can be found in a study that compared two hypotheses: that handwriting exerts its facilitative effect because of the visual-motor production of forms, and that handwriting produces variable visual instances of a character [57]. The learning experiment involved 72 five-year-old children and used Greek letters. The result of the test of the two hypotheses was clearly in favor of the second hypothesis. All groups of participants who studied multiple instances of the Greek symbols during learning performed better than the groups that were exposed only to a single, prototypical example of the symbols. Thus, the results from learning seem not a direct link between motor and perceptual systems but rather some changes in the neural system due to the variable visual instances of a named category.

Despite minimizing the role attributed to the motor-related memory in the initial learning of the characters, this result only partially supports our theory of writing, because it was found with a final recognition test. Therefore, it is worth mentioning also a recent learning experiment who tested mirror-writing with a final writing test [41]. This experiment trained 30 French children to write words and digits with their usual right hand. Each child was tested in two writing conditions: writing normally and writing under Cornell's constraints (see Section 3.4), which induced mirror writing in all 30 children aged from 4.25 to 5.00 years. The writing with a digital pen allowed the comparison between normal writing and writing in mirror by means of two kinematics parameters-velocity and fluency. Better kinematics parameters were expected in the normal writing condition, because during the learning sessions children were exposed to normal writing and trained to write normally. Surprisingly, there was no significant difference between the two conditions: Each character was produced with the same ease whether it was normally written or mirror written. It is therefore unlikely that children have learned an oriented motor pattern, because the execution of this pattern would be difficult if not impossible to reverse. 


\subsection{Is There a Differentiated Role for the Cerebral Hemispheres?}

Many authors make play a differentiated role to the two cerebral hemispheres in their theory of mirror writing [58-60]. Whereas Orton's theory [58] was shown to be difficult to reconcile with the data by Fischer and coworkers (see Section 3), Corballis' theory [60] was estimated to be compatible with these data [61]. The third theory [59] will be discussed in more depth here.

The theory proposes that mirror writing stems from proximal control. In fact, the theory is an adaptation to writing of the idea that dyslexia develops from learning the alphabet in the wrong hemisphere [62]. The theory postulates that canonical writing in the right hemi-space is controlled contralaterally by the left hemisphere, and mirror writing is controlled ipsilaterally by the right hemisphere. The theory predicts that children at-risk may process letters ipsilaterally in the right hemisphere, resulting in left hemisphere proximal movement mirror-opposed to the normal rightward direction of writing. More specifically, the theory predicts inverse reversals, that is, alphanumeric symbols that are reversed in right hemi-space but canonically printed in left hemi-space (such an inverse reversal can be seen in Figure 3, in the writings of J by Joana).

In the aim to test the theory, its author tested 159 students in Grades 1, 2, and 3, in three sorts of school in Canada: Public, Montessori, and Waldorf. Participants had systematically to write the characters $b, 3, z, 5, d, 7, s, 2, p$, and $c$ to the right and to the left of an inked line that vertically bisected their writing paper. The statistics show a main Grade effect for both simple reversal and inverse reversal. The data concerning the school are more difficult to interpret, because there was only one class by School $\times$ Grade. Nevertheless, due to anteriority of visual learning over proprioceptive learning [56], it is noteworthy that in the Montessori's school, second and third grade students mirror wrote more than in the public school, in the normal writing condition (i.e., right hemi-space). This is because the Montessori's school emphasizes proprioceptive and haptic learning (e.g., Montessori's sandpaper numerals). The author concludes that mirror writing could result from introducing writing during an ontogenetic stage of symmetrical motor function and suggests that this stage of ontogeny may be one of bilateral, proximal-motor control, during which problems arise when arm movement in beginning writing is controlled by the wrong side of the brain.

The author does not analyze the reversal of the individual characters of the series b, 3, z, 5, d, 7, s, 2, $\mathrm{p}$, and c. Nevertheless, he reproduces the writings by two first grade children. One of them (Matthew) has not produced any reversal in the normal writing condition. However, the other (Tennesson) reversed $3, z, 7$, and 2 in this condition. Thus, with the exception of $d$, this child reversed all the left-oriented characters in the sample of characters to write. When writing $d$, Tennesson already had correctly written $b$ and, perhaps, would avoid writing $b$ two times in reversing $d$. Therefore, our theory seems to explain, in great part, or even perfectly, the reversals by Tennesson in the normal condition of writing. Moreover, as illustrated by the example of Joana in Figure 3, our theory also explains the particulars of this theory [59], that is, the notion of inverse reversal. Joana simply turns the left-oriented $\mathrm{J}$ in the direction of writing. The results are a reversed $\mathrm{J}$ when writing from left to right (in the right hemi-space) and a correct J when writing from right to left (in the left hemi-space). Given that our simple theory seems explain the data in [59], the scientific principle of parsimony suggests that it is the most acceptable explanation.

\subsection{Is the Theory Compatible with All Empirical Findings?}

Given the substantial literature on mirror reversal from the 20th century, particularly in educational settings (e.g., [63-65]), it is not possible here to systematically review the data in order to examine their compatibility with the theory. Nevertheless, we will illustrate, at least with one study, how the theory can shed light on these previous findings. With participants who were mainly 1st and 2nd graders, this study found that they reverse the digits 2, 7, 3, and 9 the most frequently, and the digits 6, 5, and 4 the least frequently [66]. This finding is consistent with our theory's distinction between left-oriented and right-oriented digits, whereas the author's explanation-that some participants reversed 2,7 , and 3 because they had trouble initiating movement away from the 
midline, whereas other participants reversed 6 and 9 because they had trouble initiating movement toward the midline-seems very contrived.

\subsection{Can the Theory Be Extended to Character Recognition?}

So far, both the theory and the empirical studies carried out to test it have concentrated on the way children write characters. However, the theory raises another important question: If, as the theory holds, the mirror generalization process results in children being able to remember a character's shape but not its orientation, what arises when children read the characters? One way to examine this question is to submit children to a letter decision task. In such a task, children should say whether the writing of a character is correct or not correct, one half of the displayed characters being reversed and the other half being correct. This task was used in a first study on uppercase letters with Scottish children, and in a second study on lowercase letters with Irish children [40]. Both studies found that children who produce more reversals in writing also make more orientation recognition errors. The authors concluded that developmental mirror writing is paralleled by orientation recognition errors. However, a more classical recognition task than the letter decision task used in [40] implies a simultaneously displaying of a correctly written character and a mirror writing of this character. How do children choose which writing is correct? Because the representation activated by presenting the two writings of a character will be un-oriented, both writings should appear correct, so, logically, the children should not be able to decide which of the two is correct. Asking children to indicate which writing is the most correct (most frequently used or the best) places them in the same position as when they are asked to write a character under dictation: They have to choose between the two options. A simple extension of the theory of writing would predict that children in a left-to-right writing culture will be more likely to choose right-oriented writings as being correct, rather than left-oriented writings. Among children who have not overcome the mirror generalization process, the motor component of writing certainly biases the character's orientation towards the right in our culture. By analogy, we hypothesize that the visual component of the examination of a display of characters should bias their correct recognition towards the right spatial position, for example, towards the right column in a $2 \times 2$ table in which the target-digit and its mirror reversal are not in the same column. This precise hypothesis is currently investigated in our laboratory.

Given the educational importance of both reading and the reading disorder dyslexia [67,68], it is worth stressing that the present theory cannot be directly applied to reading. One of the reasons for this is that, in reading, children see the correct writing of the characters, so they do not have directly to make decisions about their orientation. Nevertheless, a child can be indirectly perturbed or induced into error, if a character activates its un-oriented representation in memory. Another reason is that none of the reversals of the characters reported here (digits and capital letters) are legible characters, unlike the reversals of the lowercase letters $b, d, p$, and $q$, which are the letters classically studied in investigations of reversal during reading $[25,67,69,70]$.

\section{Conclusions}

Our theory for explaining character reversals by typically developing 5-year-old children can now be summarized as follows. Typically developing children have no problems with character orientation when they see the characters (digits and capital letters), because each character's orientation is unambiguously (temporarily) encoded in the early visual areas. However, when the shape of a character is transferred to memory along the cerebral ventral pathway, a neurophysiological mirror generalization process results in the information about the character's orientation being deleted (or made inaccessible). Consequently, the representation of the character in the child's memory has no orientation. We do not exclude that the absence of orientation can in fact result from two differently oriented representations, perhaps one in each hemisphere [60], whose accesses are random or determined by situational or cultural constraints. However, the analysis for the digits [38], on the basis of a character feature set [71], suggests rather a single representation. Because it has no orientation, 
this representation cannot help a child decide how to orient a character when he or she has to write it from memory (under dictation) or choose between a correctly written character and its mirror image.

As a result, children generally choose to orient characters in the writing direction when writing from memory. This implicit, non-conscious choice is successful for all the right-oriented characters in left to right writing cultures but leads to reversal of the other asymmetrical characters $(1,2,3,7,9$, J, and Z). Making children aware of the problem of orientation, displaying the characters, and teaching 1st-grade children how to write the characters seems sufficient to enable typically developing children to restore orientation information. A well-supported theory claims that it requires inhibition of the mirror generalization process $[69,72,73]$.

A well-known maxim from the French biologist and philosopher Jean Rostand says that "theories pass, frogs remain" [74], i.e., whatever the future of our theoretical proposals will be, all theories of mirror reversal in writing by typically developing children should, from now on, try to explain the findings summarized in Section 3.

Author Contributions: Conceptualization and theorization, JPF.; Writing-Original Draft Preparation, JPF \& CL.; Writing-Review \& Editing, JPF \& CL.

Funding: This research received no external funding.

Acknowledgments: We would like to thank the two anonymous Reviewers who made constructive comments, which helped us to improve a first version of the paper.

Conflicts of Interest: The authors declare no conflict of interest.

\section{References}

1. Buchwald, A. Spiegelschrift bei Hirnkranken. Berl. Klin. Wochenschr. 1878, 5, 6-8.

2. Erlenmeyer, A. Die Schrift: Grundzüge ihrer Physiologie und Pathologie; A. Bonz: Stuttgart, Germany, 1879.

3. Hale, A.B.; Kuh, S. Mirror-writing and the inverted image. J. Amer. Med. Assoc. 1901, 37, 1380-1385. [CrossRef]

4. Scheidemann, N.V. Inverse writing: A case of consistent mirror writing. Pedagog. Semin. J. Gen. 1936, 48, 489-494. [CrossRef]

5. Hildreth, G. The development and training of hand dominance: IV. Developmental problems associated with handedness. J. Genet. Psychol. 1950, 76, 39-100. [CrossRef]

6. Simner, M.L. The grammar of action and reversals errors in children's printing. Dev. Psychol. 1984, 20, 136-142. [CrossRef]

7. Treiman, R.; Kessler, B. Similarities among the shapes of writing and their effects on learning. Writ. Lang. Lit. 2011, 14, 39-57. [CrossRef] [PubMed]

8. Lebrun, Y.; Devreux, F.; Leleux, C. Mirror-writing. In Reading and Writing Disorders in Different Orthographic Systems; Aaron, P.G., Joshi, R.M., Eds.; Kluver Academic Publishers: Dordrecht, the Netherlands, 1989; pp. 355-378.

9. Millichap, J.G. Mirror writing, a normal attribute or pathological? Pediatr. Neurol. Brief. 2000, 14, 16. [CrossRef]

10. Della Sala, S.; Cubelli, R. Directional apraxia: A unitary account of mirror writing following brain injury or as found in normal young children. J. Neuropsychol. 2007, 1, 3-26. [CrossRef] [PubMed]

11. King, L.W. Selectivity and Development of the Visual Word form Area. Ph.D. Thesis, Doctorate of philosophy, Massachusetts Institute of Technology, Camebridge, MA, USA, 2012.

12. Angelillo, V.G.; De Lucia, N.; Trojano, L.; Grossi, D. Persistent left unilateral mirror writing: A neuropsychological case study. Brain Lang. 2010, 114, 157-163. [CrossRef] [PubMed]

13. Kushnir, T.; Arzouan, Y.; Karni, A.; Manor, D. Brain activation associated with practiced left hand mirror writing. Brain Lang. 2013, 125, 38-46. [CrossRef] [PubMed]

14. McIntosh, R.D.; De Lucia, N.; Della Sala, S. Mirror man: A case of skilled deliberate mirror writing. Cogn. Neuropsychol. 2014, 31, 350-366. [CrossRef] [PubMed]

15. Buxbaum, L.J.; Coslett, H.B.; Schall, R.R.; McNally, B.; Goldberg, G. Hemispatial factors in mirror writing. Neuropsychologia 1993, 31, 1417-1421. [CrossRef] 
16. Corballis, M.C.; Beale, I.L. The Psychology of Left and Right; Erlbaum: New York, NY, USA, 1976.

17. Bornstein, M.H.; Gross, C.G.; Wolf, J.Z. Perceptual similarity of mirror images in infancy. Cognition 1978, 6, 89-116. [CrossRef]

18. Duñabeitia, J.A.; Molinaro, N.; Carreiras, M. Through the looking-glass: Mirror reading. NeuroImage 2011, 54, 3004-3009. [CrossRef] [PubMed]

19. Perea, M.; Moret-Tatay, C.; Panadero, V. Suppression of mirror generalization for reversible letters: Evidence from masked priming. J. Mem. Lang. 2011, 65, 237-246. [CrossRef]

20. Fernandes, T.; Leite, I.; Kolinsky, R. Into the looking glass: Literacy acquisition and mirror invariance in preschool and first-grade children. Child. Dev. 2016, 87, 2008-2025. [CrossRef] [PubMed]

21. Kolinsky, R.; Verhaeghe, A.; Fernandes, T.; Mengarda, E.J.; Grimm-Cabral, L.; Morais, J. Enantiomorphy through the looking glass: Literacy effects on mirror-image discrimination. J. Exp. Psychol. Gen. 2011, 140, 210-238. [CrossRef] [PubMed]

22. Pegado, F.; Nakamura, K.; Braga, L.W.; Ventura, P.; Filho, G.N.; Pallier, C.; Jobert, A.; Morais, J.; Cohen, L.; Kolinsky, R.; et al. Literacy breaks mirror invariance for visual stimuli: A behavioral study with adult illiterates. J. Exp. Psychol. Gen. 2014, 143, 887-894. [CrossRef] [PubMed]

23. Chang, C.H.C.; Pallier, C.; Wu, D.H.; Nakamura, K.; Jobert, A.; Kuo, W.J.; Dehaene, S. Adaptation of the human visual system to the statistics of letters and line configurations. NeuroImage 2015, 120, 428-440. [CrossRef] [PubMed]

24. Dehaene, S. Inside the letter box: How literacy transforms the human brain. Cerebrum 2013, 7, 1-6.

25. Dehaene, S. Reading in the Brain: The New Science of How We Read, 2nd ed.; Penguin Books: London, UK, 2010.

26. Dehaene, S. Cerebral constraints in reading and arithmetic: Education as a «neuronal recycling process. In The Educated Brain; Battro, A.M., Fischer, K.W., Léna, P.J., Eds.; Cambridge University Press: Cambridge, UK, 2008; pp. 232-248.

27. Dehaene, S. Reading in the brain revised and extended: Response to comments. Mind Lang. 2014, 29, 320-335. [CrossRef]

28. Kanwisher, N.; Dilks, D.D. The functional organization of the ventral visual pathway in humans. In The New Visual Neurosciences; Chalupa, L., Werner, J., Eds.; MIT Press: Cambridge, MA, USA, 2014; pp. 733-748.

29. Rollenhagen, J.E.; Olson, C.R. Mirror-image confusion in single neurons of the macaque inferotemporal cortex. Science 2000, 287, 1506-1508. [CrossRef] [PubMed]

30. Freiwald, W.A.; Tsao, D.Y. Functional compartmentalization and viewpoint generalization within the macaque face-processing system. Science 2010, 330, 845-851. [CrossRef] [PubMed]

31. Dilks, D.D.; Julian, J.B.; Kubilius, J.; Spelke, E.S.; Kanwisher, N. Mirror-image sensitivity and invariance in object and scene processing pathways. J. Neurosci. 2011, 31, 11305-11312. [CrossRef] [PubMed]

32. Dillon, M.R.; Hyde, D.; Spelke, E.S. Functional and spatial dissociation in the brain systems encoding object shape and direction. In Proceedings of the Poster presented at the 21st Annual Meeting of the Cognitive Neuroscience Society, Boston, MA, USA, 5-8 April 2014.

33. Fischer, J.P. Vers une levée du mystère des écritures en miroir (des chiffres) chez l'enfant. Ann. Psychol. 2010, 110, 227-251. [CrossRef]

34. Fischer, J.P. Mirror writing of digits and (capital) letters in the typically developing child. Cortex 2011, 47, 759-762. [CrossRef] [PubMed]

35. Fischer, J.P.; Tazouti, Y. Unraveling the mystery of mirror writing in typically developing children. J. Educ. Psychol. 2012, 104, 193-205. [CrossRef]

36. Fischer, J.P. Digit reversal in children's writing: A simple theory and its empirical validation. J. Exp. Child Psychol. 2013, 115, 356-370. [CrossRef] [PubMed]

37. Fischer, J.P.; Koch, A.M. La magie computationnelle de la voie ventrale est-elle à l'origine de l'inversion des lettres et des chiffres chez l'enfant de cinq à six ans? Rev. Neuropsychol. 2014, 6, 230-237. [CrossRef]

38. Fischer, J.P. Studies on the written characters orientation and its influence on digit reversal by children. Educ. Psychol.-UK 2018, 38, 556-571. [CrossRef]

39. Fischer, J.P. Vers une levée du mystère des écritures en miroir (des lettres majuscules) chez l'enfant: Une hypothèse nouvelle. Enfance 2010, 62, 371-386. [CrossRef]

40. McIntosh, R.D.; Hillary, K.; Brennan, A.; Lechowicz, M. Developmental mirror-writing is paralleled by orientation recognition errors. Laterality 2018. [CrossRef] [PubMed] 
41. Portex, M.; Hélin, C.; Ponce, C.; Foulin, J.N. Dynamics of mirror writing compared to conventional writing in typical preliterate children. Read. Writ. 2018. [CrossRef]

42. Fischer, J.P.; Koch, A.M. Mirror writing in 5- to 6-year-old children: The preferred hand is not the explanation. Laterality 2016, 21, 34-49. [CrossRef] [PubMed]

43. Fischer, J.P.; Koch, A.M. Mirror writing in typically developing children: A first longitudinal study. Cogn. Dev. 2016, 38, 114-124. [CrossRef]

44. Maass, A.; Suitner, C.; Deconchy, J.P. Living in an Asymmetrical World: How Writing Direction Affects Thought and Action; Psychology Press: London, UK, 2014.

45. Cornell, J. Spontaneous mirror-writing in children. Can. J. Psychol. 1985, 39, 174-179. [CrossRef]

46. Fischer, J.P. Character reversal in children: The prominent role of writing direction. Read. Writ. 2017, 30, 523-542. [CrossRef]

47. Nakamura, K.; Makuuchi, M.; Nakajima, Y. Mirror-image discrimination in the literate brain: A causal role for the left occipitotemporal cortex. Front. Psychol. 2014, 5. [CrossRef] [PubMed]

48. Kolers, P.A. Clues to a letter's recognition: Implications for the design of characters. J. Typograph. Res. 1969, 3, 145-168.

49. Huang, Y.; Spelke, E.S. Core knowledge and the emergence of symbols: The case of maps. J. Cogn. Dev. 2015, 16, 81-96. [CrossRef] [PubMed]

50. Treiman, R.; Gordon, J.; Boada, R.; Peterson, R.L.; Pennington, B.F. Statistical learning, letter reversals, and reading. Sci. Stud. Read. 2014, 18, 383-394. [CrossRef] [PubMed]

51. McIntosh, R.D.; Anderson, E.L.; Henderson, R.M. Experimental confirmation of a character-facing bias in literacy development. J. Exp. Child Psychol. 2018, 170, 207-214. [CrossRef] [PubMed]

52. Pommier, G. Naissance et Renaissance de L'écriture; PUF: Paris, France, 1993.

53. Chartrel, E.; Vinter, A. L'écriture: Une activité longue et complexe à acquérir. A.N.A.E. 2004, 78, 174-180.

54. Longcamp, M.; Boucard, C.; Gilhodes, J.C.; Velay, J.L. Remembering the orientation of newly learned characters depends on the associated writing knowledge: A comparison between handwriting and typing. Hum. Mov. Sci. 2006, 25, 646-656. [CrossRef] [PubMed]

55. Velay, J.L.; Longcamp, M. Clavier ou stylo: Comment écrire? Cerveau Psycho 2005, 11, 3-7.

56. Vinter, A.; Chartrel, E. Visual and proprioceptive recognition of cursive letters in young children. Acta Psychol. 2008, 129, 147-156. [CrossRef] [PubMed]

57. Li, J.X.; James, K.H. Handwriting generates variable visual output to facilitate symbol learning. J. Exp. Psychol. Gen. 2016, 145, 298-313. [CrossRef] [PubMed]

58. Orton, S.T. “Word-blindness” in school children. Arch. Neuro. Psychiatr. 1925, 14, 581-615. [CrossRef]

59. Mather, D.S. Ipsilateral printing in children's mirror-writing: A cause of specific learning disabilities? Can. J. Exp. Psychol. 2012, 66, 172-180. [CrossRef] [PubMed]

60. Corballis, M.C. Mirror-image equivalence and interhemispheric mirror-image reversal. Front. Hum. Neurosci. 2018, 12. [CrossRef] [PubMed]

61. Mather, D.S. Does dyslexia develop from learning the alphabet in the wrong hemisphere? A cognitive neuroscience analysis. Brain Lang. 2001, 76, 282-316. [CrossRef] [PubMed]

62. Fischer, J.P.; Luxembourger, C. Commentary: Mirror-image equivalence and interhemispheric mirror-image reversal. Front. Hum. Neurosci. [Paper accepted].

63. Legrün, A. Spiegelschrift bei Schulneulingen. Z. Pädagog. Psychol. Jug. 1931, 32, 547-557.

64. Hildreth, G. Reversals in reading and writing. J. Educ. Psychol. 1934, 25, 1-20. [CrossRef]

65. Lewis, E.R.; Lewis, H.P. An analysis of errors in the formation of manuscript letters by first-grade children. Am. Educ. Res. J. 1965, 2, 25-35. [CrossRef]

66. Zaslow, R.W. Reversals in children as a result of midline body orientation. J. Educ. Psychol. 1966, 57, $133-139$. [CrossRef] [PubMed]

67. Lachmann, T. Experimental approaches to specific disabilities in learning to read: The case of symmetry generalization in developmental dyslexia. In Advances in Cognitive Science; Srinivasan, N., Gupta, A.K., Pandey, J., Eds.; Sage: Thousand Oaks, CA, USA, 2008; pp. 321-342.

68. Fernandes, T.; Leite, I. Mirrors are hard to break: A critical review and behavioral evidence on mirror-image processing in developmental dyslexia. J. Exp. Child Psychol. 2017, 159, 66-82. [CrossRef] [PubMed] 
69. Borst, G.; Ahr, E.; Roell, M.; Houdé, O. The cost of blocking the mirror generalization process in reading: Evidence for the role of inhibitory control in discriminating letters with lateral mirror-image counterparts. Psychon. B. Rev. 2015, 22, 228-234. [CrossRef]

70. Brault-Foisy, L.M.; Ahr, E.; Masson, S.; Houdé, O.; Borst, G. Is inhibitory control involved in discriminating pseudowords that contain the reversible letters b and d? J. Exp. Child Psychol. 2017, 162, 259-267. [CrossRef] [PubMed]

71. Schubert, T.M. Why are digits easier to identify than letters? Neuropsychologia 2017, 95, 136-155. [CrossRef] [PubMed]

72. Ahr, E.; Borst, G.; Houdé, O. The learning brain: Neuronal recycling and inhibition. Z. Psychol. 2016, 224, 277-285. [CrossRef]

73. Ahr, E.; Houdé, O.; Borst, G. Inhibition of the mirror generalization process in reading in school-aged children. J. Exp. Child Psychol. 2016, 145, 157-165. [CrossRef] [PubMed]

74. Rostand, J. Carnet d'un Biologiste; Stock: Paris, France, 1959.

(C) 2018 by the authors. Licensee MDPI, Basel, Switzerland. This article is an open access article distributed under the terms and conditions of the Creative Commons Attribution (CC BY) license (http:/ / creativecommons.org/licenses/by/4.0/). 